\title{
Viewing the Cerebellum through the Eyes of Ramón Y Cajal
}

\author{
Constantino Sotelo
}

(C) Springer Science + Business Media, LLC 2008 the planning and execution of the movement, but that has access also to higher cognitive functions.

Keywords History of the cerebellar circuitry · Neuroanatomy

In volume two of his autobiography devoted to the "History of my Scientific Work", Santiago Ramón y Cajal [1] reported that, in 1888, after a year of intense research and of investigation of many regions of the avian and mammalian CNS using the Golgi method, he selected the avian cerebellum for his first paper on the CNS since it offered him the first glimpse on how the brain was organized. Indeed, the first evidences in favor of his neuron doctrine, including the laws that govern the morphology and the connections of nerve cells, arose from the cerebellum study.

What is really amazing is to be able to follow the progression of Cajal's ideas from his first steps to the ultimate comprehensive description of the cerebellum circuitry, which took less than 3 years. In his first publication [2], baskets were indistinguishable from stellate cells, and both types of axons participated in the formation of pericellular baskets around Purkinje cell (PC) bodies (Fig. 1a). The concept that these neurons represent one continuously varying population is nowadays considered correct [3, 4]. More importantly, Cajal found that, as opposed to Golgi's ideas, these descending axons did not establish anastomoses with other axons but instead terminated freely. Granule cell bodies and dendrites were accurately described; however, Cajal missed part of their ascending axons. He wrote: "we have never seen such fibers enter the molecular layer nor bend toward the white matter" (Fig. 1a), even if he considered that these axons might - through lateral branchlets - contact PCs. He also reported what he later on called climbing (CFs; here called 


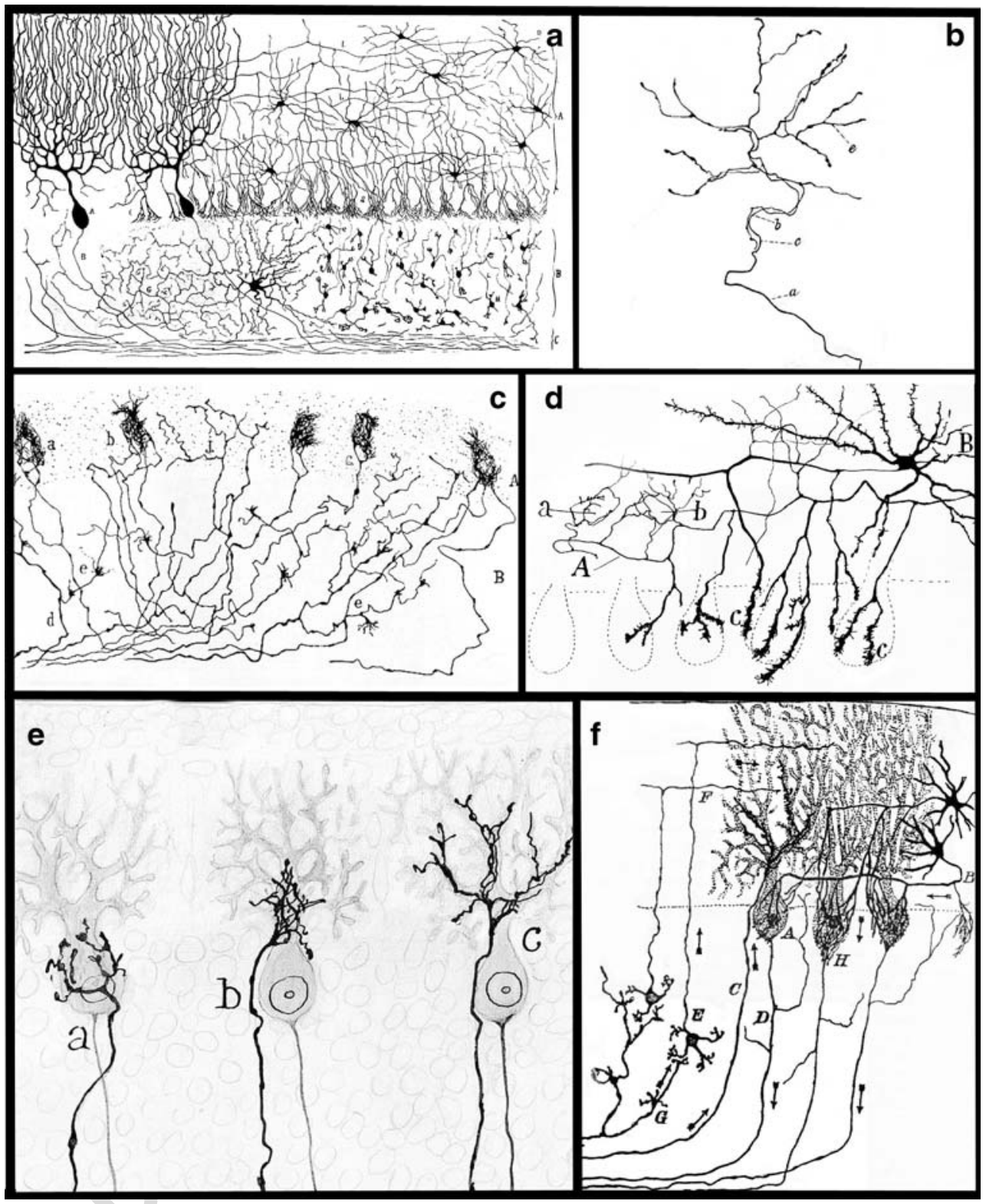

Fig. 1. Cajal's illustrations of his studies to unravel the circuitry of the cerebellum. a First drawing published in May 1888 illustrating the three-layered cortex of the cerebellum and their containing neuronal types: stellate cells in the molecular layer, Purkinje cells in the ganglionic cell layer at the interface between molecular and granular layers, and granule cell layer with its granule and Golgi cells. Note that the axons of the granule cells do not enter into the molecular layer, and that the axons of the stellate cells end freely, forming a basket around the Purkinje cell bodies. Three months later, in August 1888, climbing fibers were described in detail in the sparrow cerebellum under the name of "vertical fibers", and were nicely illustrated in 1889 (b). c Drawing of the cerebellum of a newborn dog describing the cerebellar nests formed by either one of several

"vertical varicose fibers") and mossy fibers (MFs; here called "knotty fibers"), but did not speculate about their possible origins or their connections. The most impressive part of the study was Cajal's description of PCs with their free axons entering the white matter after providing ascending fibers emerging from the white matter, interpreted by Cajal as a new class of afferent fibers. Note also the presence of mossy fibers in the granular layer. $\mathbf{d}$ Copy of a basket cell of the guinea pig illustrated in figure 376 of the "Textura" (1904). e Schematic representation of the three temporal phases in the formation of climbing fiber-Purkinje cell synapses. $a$ pericellular nest, $b$ capuchon stage, and $c$ young climbing fiber, allowing Cajal to recognize that the cerebellar nests were only a transient step in the somatodendritic translocation of the climbing fibers during development. f Copy of the figure 5 of the "Croonian Lecture" published in 1894 showing the connections of the Purkinje cells and the direction of nerve impulses (arrows) within the cerebellar circuit

recurrent collaterals that terminated forming the subganglionic plexus and his discovery of dendritic spines (Fig. 1a). At first, he believed that "these protrusions were the result of silver precipitate; but their constant occurrence and their presence even in preparations where the impreg- 
Cerebellum

nation appeared with extreme daintiness in the remaining elements, prompted us to consider them as a normal trait". However, 3 months later, in his second publication, Cajal [5] reported the parallel fibers to be the terminal fields of granule cell axons, a description which was completed in a review paper published in French some months later [6]. In addition, he reported fine brush terminations of the basket fibers around the initial segment of the PC axon, the "pinceau formation" (Fig. 1d), and published the first detailed description of CFs [7]: "they appear to be formed of two fibers, one thick and continuous with the stem, the other thin and weakly impregnated...that arise from the principal stem or one of its thick branches" (Fig. 1b).

The material used for his third publication [7] was newborn and 1-month-old dogs, and of 15-day-old cats. Even though the partially myelinated status of this material allowed him a better impregnation, it was also a cause of confusion. Indeed, from the newborn dog to the 15-day-old cat, CFs have translocated from their pericellular stage to the peridendritic mature location. Without knowing the intermediate stages, their identification was impossible, and Cajal described them as a new type of fibers (Fig. 1c) appearing in the mammalian cerebellum, which emerged from the white matter and ascended up to the PC layer where they ramified profusely - as a bird nest - around the cell bodies of the PCs, with an inverted position to basket axons. He called these fibers cerebellar nests, but in February 1890 [8], with the continuous use of immature animals and the identification of the missing intermediate steps, Cajal admitted his misinterpretation and reported the whole process of the developmental stages of these fibers (Fig. 1e), coined from now on climbing fibers.

In 3 years of work, Cajal had in his hands all the elements that comprise the organization of the cortical circuitry of the cerebellum and the routes followed by the impulses reaching this cortex. But, as previously commented, this study had much more general implications than those confined to the cerebellum itself. Indeed, the occurrence of basket cells, with their peculiar pericellular baskets and pinceaux formations ending freely around PC bodies and axonic initial segments, together with the correct interpretation of the developmental history of the CFs, and their ultimate disposition coiling up along the main branches of the PC dendrite, prompted Cajal to conceive that the nervous system was not formed by a broad network of random processes, as speculated in the "reticularist" conception of Gerlach and Golgi. On the contrary, the free terminations of the cerebellar axons provided Cajal solid morphological evidence in favor of the fact that the cell theory also applies to the nervous tissue. The cerebellum became, therefore, the spearhead used by Cajal to convince the majority of his contemporary scientists that the nervous system was not an exception and that the cell theory championed by Rudolph Virchow was also related to the nervous system. This essential biological perception of the living organisms implies that all the tissues are organized according to the same principle, which is that the smallest living independent unit is the cell. In a sense, the cellular theory can be perceived as revolutionary as the atomic theory in physics, opening a new era in the history of biology. This drastic change, considering that between the nerve cell processes there is no continuity, only contiguity, has provided the basis upon which modern neuroscience stands: the nervous system is composed of billions of independent, richly and precisely interconnected nerve cells, later named neurons [9], organized into specific functional circuits.

One of the peculiarities of Cajal's discoveries has been his constant interest in adapting the morphological data to functional considerations. Between 1888 and 1894, the latter being the year he was invited by the Royal Society to deliver the Croonian Lecture [10], Cajal had disclosed the circuitries of various other regions of the CNS, mostly the retina, spinal cord, olfactory bulb, and the beginning of his analysis of the cerebral cortex. With this experience, and in corroboration with the neuronal doctrine in the just-cited centers, Cajal inferred that, since dendritic and axonic arbors end independently, the dendrites must have "conductive" rather than nutritive functions, as speculated by Golgi, offering to Cajal the possibility to formulate his "law of dynamic polarization", a basic principle of the functioning of neuronal connections. This law considers that all neurons are dynamically polarized in such a way that excitation can only be transmitted from the axon of one neuron to the dendrites or soma of another, and, within a neuron, this excitation travels from the dendritic pole to the axonal pole. Concerning the cerebellum, the typical "Indian arrows" drawn by Cajal ([10]; Fig. 1f) pointed to the route taken by nerve impulses reaching the cortex through mossy and climbing fibers. These impulses did not travel randomly but instead followed stereotypic pathways. Therefore, in 3 years of intense work, Cajal was capable of revealing the organization of the cerebellar circuitry, even though the concept of inhibition was completely ignored.

The pioneering work of Cajal is the base of our present knowledge on the anatomical organization of the cerebellum. Even though the root of such a circuitry remains unchanged, many important new data have been gathered during the last 120 years. The majority of the post-Cajal discoveries are the result of the application of new techniques. The functional anatomy of the cerebellar system really started with the Nauta's staining, a selective silver method that only impregnates degenerating fibers, capable of revealing that all CFs arise from inferior olivary neurons [11], whereas mossy fibers are a composite 
186

187

188

189

190

191

192

193

194

195

196

197

198

199

200

201

202

203

204

205

206

207

208

209

210

211

212

213

214

215

216

217

218 population originated from neurons in the spinal cord, medulla oblongata, pons, and primary as well as secondary vestibular fibers. In addition, Nauta's method demonstrates the organization plan of these two major afferent systems according to a precise spatial order resulting from the axonal segregation into distinct cortical compartments disposed in adjacent parasagittal bands, the so-called longitudinal zonal organization of the cerebellum [12]. This important part of our knowledge was greatly extended and refined during the 1970s, when anterograde and retrograde axon tracing methods, based upon axonal flows, were developed [13]. A qualitative jump in the functional anatomy of the cerebellum, due to its important implications, was performed by Peter Strick [14]. Even though same suggestions that part of the cerebellar output could project to non-motor cortex were previously advanced, it was the use of a new axonal tracing technique, the anterograde and retrograde transneuronal transport of different types of viruses, that, in the hands of Middleton and Strick [14], allowed a most remarkable discovery; the demonstration that neurons in the basal ganglia and cerebellum innervated areas of the cerebral cortex involved in cognitive function. These investigators demonstrated that many neurons in precise regions of the cerebellar dentate nucleus and in the internal segment of the globus pallidus could be labeled by the transneuronal viral transport from Walker's area 46 of the primate dorsolateral prefrontal cortex, an area involved in spatial working memory. Therefore, the cerebellum does not only contribute, through their interconnections with the motor cortex, to the planning and execution of the movement but also, through its connections with the prefrontal cortex, access higher cognitive functions.

With the above cited example, it is of interest to recall that today, neuromorphologists are living in a somewhat similarly innovative period to that experienced by Cajal after the technical breakthrough provided by Golgi [15] with his silver impregnation method. Thus, the longed for wish of neuromorphologists to correlate the chemical constituents of the neuron with their structural counterparts, as a valuable approach to better appraise neuronal function and organization, is now a reality. In the last 50 years, great technological advances emerging from physics, chemistry, and molecular biology have revolutionized the field and breathed new life into this morphological approach. These main advances in what I would call modern neuromorphology have made this field one of the most rapidly expanding ones of all the neurosciences, and have greatly contributed to the current concept of the cerebellum. Allow me to mention what I consider to be important advances, together with the methodologies developed along the past 50 years.

The development of electron microscopy (EM) and the techniques for its application to the study of the CNS (fixation, embedding, and preparation of ultrathin sections) opened a new field of study, which, in parallel with the intracellular recordings [16], provided complete knowledge of the synaptic organization of the cerebellar cortex [17]. Moreover, through anterograde axon degeneration, the origin of mossy and climbing fibers was corroborated [18, 19], and their precise sites of termination revealed. In this manner, some previous interpretations of Golgi-impregnated CFs were either denied or confirmed. For instance, CFs have no collaterals within the granular layer as suggested [20] and, on the contrary, they provide a few collaterals in the molecular layer (Scheibels' collaterals; [21]) synapsing on interneurons (unpublished results, Fig. 2a,b), despite their refuted existence [22]. In addition, the discovery that GABAergic interneurons were coupled through gap junctions [23] was of interest due to its potential role in the electrical signaling of network activity, particularly its role in the generation of loosely synchronous activity, which results from the interaction of electrical coupling and intrinsic currents ([24]; Fig. 2c-e).

Our understanding of the fine organization of the cerebellum has been incremented by new knowledge acquired with what I will call "histochemical methods". Thus, from the histofluorescent methods to the study of monoaminergic systems, which allows the identification of new extracerebellar afferent fibers arising from the locus coeruleus and some raphe nuclei [25], and ending with a non-junctional modality or paracrine way of modulatory interaction $[26,27]$, to the immunocytochemical and in situ hybridization methods, have afforded an almost complete view on neurotransmitters and receptors involved in cerebellar function. Cajal should be extremely happy with all these new developments. Nevertheless, he would be surprised to learn about the fact that his beloved Golgi method has been capable of generating novel information on cortical interneurons, firstly with a much better understanding of the morphology and connections of Lugaro cells, and finally with the discovery of new types of interneurons such as the candelabrum cells [28] and most importantly the unipolar brush cells (UBC) [29]. The latter, similar to those reported by Hockfield [30] using the monoclonal antibody Rat-302, have modified our concept of the cerebellar circuitry by adding a new class of glutamatergic interneuron at the origin of intrinsic mossylike fibers, and have ended with the frequently used description that this cortex is characterized by its uniform anatomical organization with a uniform mircrocircuitry. Indeed, UBC are not uniformly distributed throughout the cortex but instead are distributed in the ventral lobules, particularly the X to VIII.

This short outline of what I consider the post-Cajal advances in the understanding of the organization and functions of the cerebellum is, of course, incomplete and 
Cerebellum

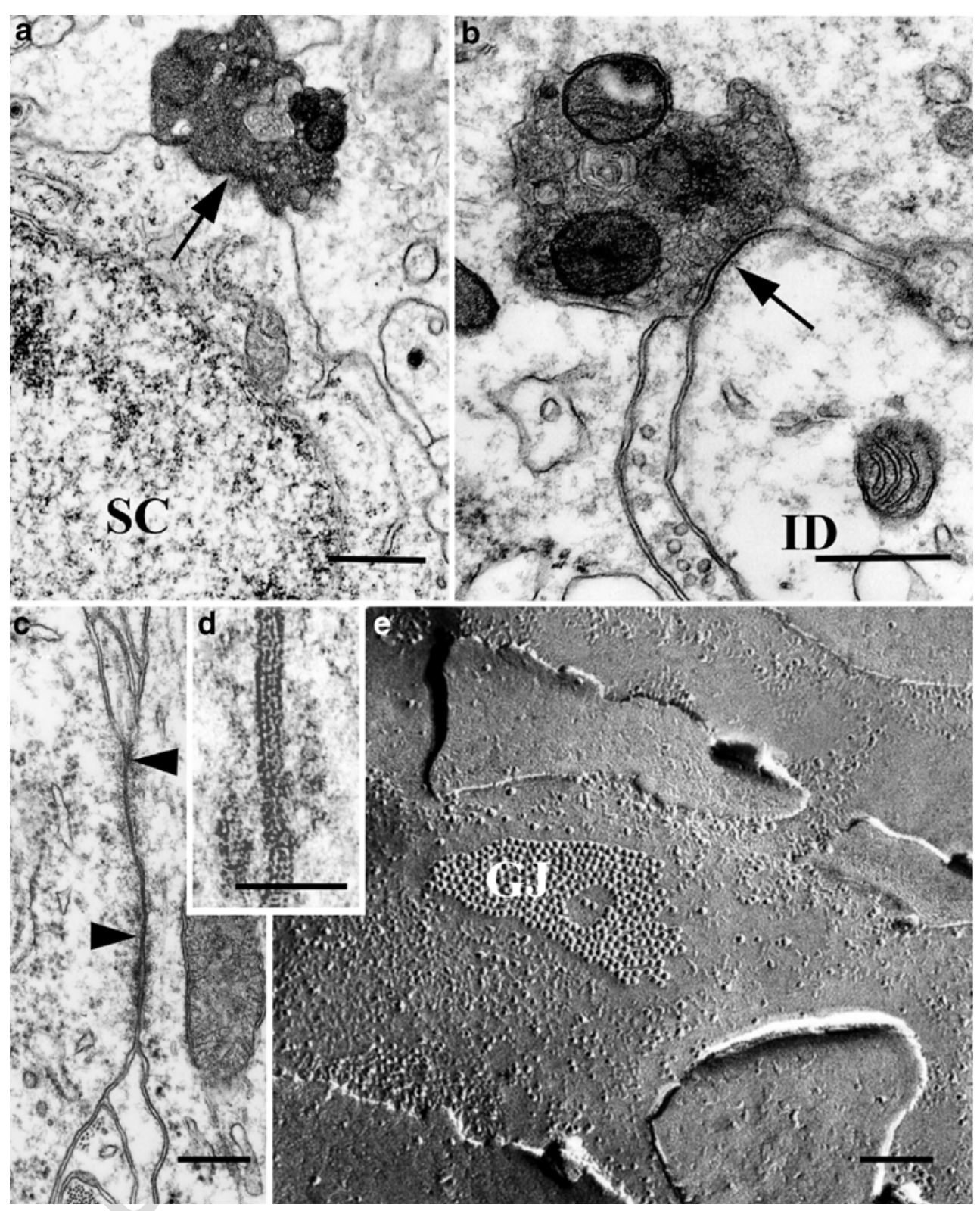

Fig. 2. a, b Electron micrographs taken from an adult rat with a chemical destruction of the inferior olivary complex produced by an intraperitoneal injection of 3-acetyl-pyridine $(65 \mathrm{mg} / \mathrm{kg}$ body weight $)$ $24 \mathrm{~h}$ before the intracardiac perfusion. a The dark degenerating terminal, belonging to a climbing fiber, is apposed to the cell body of a stellate interneuron (SC) located in the upper half of the molecular layer (arrow points to the synaptic region). b This micrograph was taken from the lower half of the molecular layer. A dark degenerating axon terminal, belonging to a climbing fiber, establishes a synaptic contact (arrow) on the smooth surface of an interneuron dendrite (ID), which may belong to a basket cell. c Molecular layer of the cat cerebellum. Direct

subjective. Nonetheless, it has the merit to emphasize the central position of the neuroanatomy in today's study of the cerebellum. To understand how genes govern the development and regulate the function of this nervous center, it is essential to determine their precise cellular expression and apposition between a basket cell body and a large dendritic profile probably belonging to another basket cell. This zone of direct apposition is formed by a large gap junction (between arrowheads) illustrated at higher magnification in (d). Note the heptalaminar appearance of this somatodendritic gap junction and the cytoplasmic densities at both sides of the gap junction. e Freeze fracture of the rat cerebellum illustrating a gap junction plaque $(G J)$ between the plasma membranes of two apposed basket cell bodies in the lower half of the molecular layer. The fracture plane of the gap junction shows the $\mathrm{P}$ face, which contains numerous diffused intramembrane particles. Scale bar in $\mathbf{a}, \mathbf{b}=0.5 \mu \mathrm{m}$; in $\mathbf{c}=0.25 \mu \mathrm{m}$; and in $\mathbf{d}, \mathbf{e}=0.1 \mu \mathrm{m}$

their dynamic changes. This is the principal aim of modern neuroanatomy. Cajal was a pioneer in providing the bases upon which our present knowledge of the organization of the cerebellum rely. However, despite the great here mentioned advances, we are still far from a complete 
understanding of its function. I am sure that Cajal, who was also a trailblazer in demonstrating that the answer of outstanding questions depends on the use of appropriate and reliable techniques, would be enthusiastic with the current anatomical tools offered today for the study of the nervous system and particularly his beloved cerebellum.

\section{References}

1. Cajal SR (1917) Historia de mi labor científica. In: Recuerdos de mi vida. Vol. 2, Madrid: Nicolas Moya

2. Cajal SR (1888) Estructura de los centros nerviosos de las aves. Rev Trim Histol Norm Patol 1:1-10

3. Sultan F, Bower JM (1998) Quantitative Golgi study of the rat cerebellar molecular layer interneurons using principal component analysis. J Comp Neurol 393:353-373

4. Leto K, Carletti B, Williams IM, Magrassi L, Rossi F (2006) Different types of cerebellar GABAergic interneurons originate from a common pool of multipotent progenitor cells. J Neurosci $26: 11682-11694$

5. Cajal SR (1888) Sobre las fibras nerviosas de la capa molecular del cerebelo. Rev Trim Histol Norm Patol 2:33-41

6. Cajal SR (1889) Sur l'origine et la direction des prolongations nerveuses de la couche moléculaire du cervelet. Int Msch Anat Physiol 6:158-174

7. Cajal SR (1889) Sobre las fibras nerviosas de la capa granulosa del cerebelo. Rev Trim Histol Norm Patol 4:107-118

8. Cajal SR (1890) À propos des certains éléments bipolaires du cervelet avec quelques détails nouveaux sur l'évolution des fibres cérébelleuses. Int Msch Anat Physiol 1890;7:12-30. French translation of the Spanish paper: Sobre ciertos elementos bipolares del cerebelo joven y algunos detalles más acerca del crecimiento y evolución de las fibras cerebelosas. Gaceta Sanitaria de Barcelona

9. Waldeyer HWG (1891) Über einige neuere Forschungen im Gebiete der Anatomie des Centralnervensystems. Dtsch Med Wochenschr 17:1213-1218 1244-1246, 1267-1269, 1287-1289, 1331-1332, and 1352-1356

10. Cajal SR (1894) The Croonian Lecture: la fine structure des centres nerveux. Proc R Soc (Lond) 55:444-468

11. Szentagothai J, Rajkovits K (1959) The origin of the climbing fibers of the cerebellum. Z Anat EntwgGesch 121:130-141

12. Voogd J (1969) The importance of fiber connections in the comparative anatomy of the mammalian cerebellum. In: Llinás R (ed) Neurobiology of cerebellar evolution and development. American Medical Association, Chicago, pp 493-514

13. LaVail JH, LaVail MM (1972) Retrograde axonal transport in the central nervous system. Science 176:1416-1417
14. Middleton FA, Strick PL (1994) Anatomical evidence for cerebellar and basal ganglia involvement in higher cognitive function. Science 266:458-461

15. Golgi C (1873) Sulla struttura della sostanza grigia del cervello. Gazzette Medica Italiana-Lombardia 6:244-246

16. Eccles J, Llinas R, Sasaki K (1964) Excitation of cerebellar Purkinje cells by the climbing fibres. Nature 203:245-246

17. Palay SL, Chan-Palay V (1974) Cerebellar cortex. Cytology and organization. Springer, Berlin

18. Angaut P, Sotelo C (1975) Diversity of mossy fibres in the cerebellar cortex in relation to different afferent systems: an experimental electron microscopic study in the cat. Brain Res 95:179-189

19. Sotelo C, Hillman DE, Zamora AJ, Llinás R (1975) Climbing fiber deafferentation: its action on Purkinje cell dendritic spines. Brain Res 98:574-581

20. Chan-Palay V, Palay SL (1971) Tendril and glomerular collaterals of climbing fibers in the granular layer of the rat's cerebellar cortex. Z Anat EntwgGesch 133:247-273

21. Scheibel ME, Scheibel AB (1954) Observations on the intracortical relations of the climbing fibers of the cerebellum: a Golgi study. J Comp Neurol 101:733-763

22. Hámori J, Szentágothai J (1980) Lack of evidence of synaptic contacts by climbing fibre collaterals to basket and stellate cells in developing rat cerebellar cortex. Brain Res 186:454-457

23. Sotelo C, Llinás R (1972) Specialized membrane junctions between neurons in the vertebrate cerebellar cortex. J Cell Biol 53:271-289

24. Mann-Metzer P, Yarom Y (1999) Electrotonic coupling interacts with intrinsic properties to generate synchronized activity in cerebellar networks of inhibitory interneurons. J Neurosci 19:3298-3306

25. Hökfelt T, Fuxe K (1969) Cerebellar monoamine nerve terminals, a new type of afferent fibers to the cortex cerebelli. Exp Brain Res 9:63-72

26. Beaudet A, Sotelo C (1981) Synaptic remodeling of serotonin axon terminals in rat agranular cerebellum. Brain Res 206:305329

27. Abbott LC, Sotelo C (2000) Ultrastructural analysis of catecholaminergic innervation in weaver and normal mouse cerebellar cortices. J Comp Neurol 426:316-329

28. Lainé J, Axelrad H (1994) The candelabrum cell: a new interneuron in the cerebellar cortex. J Comp Neurol 339:159-173

29. Mugnaini E, Floris A (1994) The unipolar brush cell: a neglected neuron of the mammalian cerebellar cortex. J Comp Neurol 339:174-180

30. Hockfield S (1987) A Mab to a unique cerebellar neuron generated by immunosuppression and rapid immunization. Science 237:67-70 


\section{AUTHOR QUERY}

\section{AUTHOR PLEASE ANSWER QUERY.}

No Query. 